\title{
COMPARAÇÃO ENTRE DIVERSOS SUBSTRATOS NO ENRAIZAMENTO DE ESTACAS DE CRÓTON (Codiaeum variegatum L.)
}

\author{
M.A.A. TILLMANN \\ Departamento de Fitotecnia - FAEM/UFPel - C.P. 34, CEP: 96100-970 - Pelotas, RS \\ C. CAVARIANI \\ Departamento de Agricultura e Melhoramento Vegetal - FCA/UNESP - C.P. 237, CEP: 18603-970 - Botucatu,SP \\ Z. PIANA \\ Empresa de Pesquisa Agropecuária e Difusão de Tecnologia - EPAGRI - C.P. 502, CEP: 88034-901 - Florian6polis,SC \\ K. MINAMI \\ Departamento de Horticultura - ESALQ/USP - C.P. 9, CEP:13418-900 - Piracicaba,SP
}

RESUMO: Com o objetivo de determinar o melhor substrato para o enraizamento de estacas de cróton (Codiaeum variegatum L.), utilizou-se areia, vermiculita média, areia x vermiculita (75\% x 25\%); (50\% x 50\%); $(25 \% \times 75 \%)$, esponja fenólica e solo. $O$ experimento foi conduzido em câmara de nebulização com delineamento em blocos casualizados com quatro repetiçōes de vinte estacas cada. Determinaram-se as propriedades físicas dos substratos e foram efetuadas as seguintes avaliaçōes: porcentagem de estacas enraizadas, porcentagem de estacas brotadas, número de rázes por estaca, comprimento da maior raiz e peso da matéria seca das raízes. Os resultados permitem concluir que o substrato vermiculita média é o mais indicado para 0 enraizamento de estacas de cróton, embora os demais, exceto o solo e areia que apresentaram os piores desempenhos, também possam ser utilizados.

Descritores: croton, Codiaeum variegatum, substratos, estacas, enraizamento

\section{COMPARISON AMONG SEVERAL MEDIA FOR THE ROOTING OF CROTON (Codiaeum variegatum L.) CUTTINGS}

\begin{abstract}
ARSTRACT: To determine the best medium for rooting of croton (Codiaeum variegatum L.) cuttings, the media: sand, medium grade vermiculite, sand x vermiculite (75\% x 25\%); (50\% x 50\%); (25\% x 75\%), phenolic foam and soil were used. The experiment was conducted in a mist chamber in a randomized block design with four replications of twenty cuttings each. The physical properties of the media were determined and the following evaluations made: rooted cutting percentage, shooted cutting percentage, number of roots per cutting, lenght of the longest root, and weight of root dry matter. The results show that the medium grade vermiculite medium is the most suitable for the rooting of croton cuttings although the others may also be used, except soil and sand which presented the poorest performances.
\end{abstract}

Key Words: croton, Codiaeum variegatum, media, cuttings, rooting

\section{INTRODUÇÃO}

Os crótons pertencem à família das Euphorbiaceas, originários da Ásia e das Ilhas do Pacífico, destacando-se algumas espécies e variedades com o nome vulgar de Independência, devido às cores predominantes verde e amarelo. São plantas ornamentais e servem para formar bosques coloridos e corbelhas (FIGUEIREDO, 1936).

Existem mais de cem variedades de crótons, apresentando cores variadas: amarela, verde, cobre, vermelha, rosa, laranja, marrom e marfim (PLANTAS de interior, 1977).

Das numerosas espécies cultivadas em jardins destaca-se a Codiaeum variegatum $\mathbf{L}$., arbusto de $3 \mathrm{~m}$ de altura, objeto deste estudo.

Os crótons propagam-se por meio de estacas, de abril a agosto (PLANTAS de interior, 1977 e FIGUEIREDO, 1936) e por alporquia, na primavera ou verão (PLANTAS de interior, 1977). Duas restrições ao emprego da alporquia são a grande demanda de mão-de-obra e a dificuldade operacional. 
Um dos fatores mais importantes para - enraizamento de estacas $\epsilon$ o substrato, dentre outros como: controle de temperatura, umidade e controle de doenças.

Este experimento teve por objetivo determinar o melhor substrato para o enraizamento de estacas de cróton.

\section{MATERIAL E MÉTODOS}

O experimento foi conduzido em câmara de nebulização, na área experimental do Departamento de Horticultura da Escola Superior de Agricultura "Luiz de Queiroz"/USP em Piracicaba, SP, no período de março a junho de 1992.

Para o teste dos substratos foram utilizadas estacas apicais de cróton (Codiaeum variegatum L.). As estacas tinham em média $16 \mathrm{~cm}$ de comprimento e $0,7 \mathrm{~cm}$ de diâmetro.

As estacas foram colocadas para enraizar em caixas de poliestireno expandido com células individuais em forma de pirâmide invertida de $5 \times 5 \mathrm{~cm}$ e $12 \mathrm{~cm}$ de profundidade, contendo os substratos.

Antes de colocar as estacas nos substratos, estes foram regados e a umidade foi mantida por meio de nebulizações, em intervalos regulares, através de controle automático, em câmara de nebulização.

As propriedades físicas dos substratos utilizados, indicados estão na TABELA 1. O delineamento experimental utilizado foi blocos casualizados, com 4 repetições por tratamento (substratos), contendo 20 estacas por repetição, fincadas a uma profundidade de $5 \mathrm{~cm}$.

$A$ avaliação foi realizada no final do período experimental, aos 50 dias, tendo sido avaliados os seguintes parâmetros: 1) porcentagem de estacas enraizadas; 2) porcentagem de estacas brotadas; 3) número de raízes por estaca; 4) comprimento da maior raiz; 5) peso da matéria seca das raízes.

No período experimental foi realizado o monitoramento do enraizamento das estacas através da observação visual de estacas de bordadura.

Através da análise da variância foram feitas as comparações entre médias de tratamentos pelo teste de Tukey a $5 \%$ de probabilidade de erro.

\section{RESULTADOS E DISCUSSÃo}

Os resultados das avaliações são mostrados na TABELA 2.
Pela avaliação da porcentagem de estacas enraizadas, observou-se que os substratos areia e solo não diferiram entre si e foram inferiores aos demais, exceção feita ao tratamento areia $(\mathbf{7 5 \%}) \times$ vermiculita $(25 \%)$.

Embora não tenham diferido estatisticamente dos melhores tratamentos, os substratos vermiculita média e esponja fenólica apresentaram os maiores valores absolutos.

$\mathrm{Na}$ avaliação de estacas brotadas, os substratos testados não diferiram entre si. Entretanto, igualmente ao verificado para estacas enraizadas, os substratos vermiculita média e esponja fenólica apresentaram os maiores valores em termos absolutos. Para avaliação de substratos para enraizamento de estacas apicais de cróton, o parâmetro estacas brotadas não foi um bom critério de avaliação, pois não permitiu evidenciar diferenças estatísticas significativas entre os substratos analisados.

Com relação ao parâmetro número de raizes por estaca, verificou-se que os substratos vermiculita média, areia $(75 \%) \times$ vermiculita (25\%) e areia (50\%) $x$ vermiculita (50\%) possibilitaram o melhor enraizamento, sendo que o substrato solo mostrou o menor número de raízes por estaca.

O parâmetro comprimento da maior raiz revelou que o substrato areia $(25 \%) \times$ vermiculita (75\%) apresentou o melhor desempenho, embora não tenha diferido dos demais, com exceção do substrato solo, que apresentou o pior desempenho.

Em relação ao peso da matéria seca das raízes, os substratos mais indicados foram vermiculita média e areia $x$ vermiculita, nas proporçóes: $50 \% \times 50 \%$ e $25 \%$ × $75 \%$ e, os substratos solo e areia os menos indicados.

Através de todas as avaliações efetuadas observou-se que os substratos solo e areia apresentaram os piores desempenhos para 0 enraizamento de estacas de cróton, sendo o substrato vermiculita o mais indicado.

Comparando-se as propriedades fisicas da vermiculita média, solo e areja (TABELA 1), observa-se que o primeiro substrato apresenta maior espaço poroso total, maior retenção de água e espaço de ar, e menor densidade. GONCCALVES et al. (1991) estudando o efeito de diferentes substratos no enraizamento de estacas apicais e não apicais de Rhipsalis elliptica constataram que a vermiculita estava entre os melhores tratamentos. Em trabalho de enraizamento com Crisântemo (Chrysanthemum morifolium cv. Polaris), 
TABELA 1 - Propriedades físicas dos substratos utilizados no experimento.

\begin{tabular}{|c|c|c|c|c|}
\hline \multirow[b]{3}{*}{ Substrato } & \multicolumn{4}{|c|}{ Propriedades físicas } \\
\hline & Densidade & $\begin{array}{c}\text { Espaço } \\
\text { poroso total }\end{array}$ & $\begin{array}{l}\text { Retenção de água } \\
\text { na cap. de campo }\end{array}$ & $\begin{array}{l}\text { Espaço de ar na } \\
\text { capacidade de campo }\end{array}$ \\
\hline & $\mathrm{g} / \mathrm{cm}^{3}$ & $\%$ & $\%$ & $\%$ \\
\hline 1. Areia & 1,34 & 78,5 & 50,14 & 28,36 \\
\hline 2. Vermiculita média & 0,12 & 137,5 & 73,45 & 64,05 \\
\hline $\begin{array}{l}\text { 3. Areia e vermiculita } \\
(75: 25)\end{array}$ & 1,26 & 78,0 & 65,48 & 12,53 \\
\hline $\begin{array}{l}\text { 4. Areia e vermiculita } \\
(50: 50)\end{array}$ & 0,91 & 86,0 & 71,13 & 14,88 \\
\hline $\begin{array}{l}\text { 5. Areia e vermiculita } \\
(25: 75)\end{array}$ & 0,59 & 101,5 & 76,28 & 25,23 \\
\hline 6. Esponja fenólica & 0,015 & 251,0 & 119,00 & 132,00 \\
\hline 7. Solo & 1,10 & 91,0 & 66,41 & 24,60 \\
\hline
\end{tabular}

Fonte: FRETZ et al. (1979).

TABELA 2 - Avaliação de substratos para enraizamento de estacas de cróton (Codiaeum variegatum)'.

\begin{tabular}{|c|c|c|c|c|c|}
\hline Substrato & $\begin{array}{c}\text { Estacas } \\
\text { enraizadas } \\
(\%)\end{array}$ & $\begin{array}{c}\text { Estacas } \\
\text { brotadas } \\
(\%)\end{array}$ & $\begin{array}{c}\begin{array}{c}\text { Raízes } \\
\text { por estaca }\end{array} \\
\left(\mathrm{n}^{0}\right)\end{array}$ & $\begin{array}{l}\text { Comprimento } \\
\text { da maior raiz } \\
\text { (cm) }\end{array}$ & $\begin{array}{c}\text { Peso da } \\
\text { matéria seca } \\
\text { das raízes } \\
\text { (g) }\end{array}$ \\
\hline 1. Areia & $63 \mathrm{~b}$ & $85 n s$ & $6 \mathrm{ab}$ & $5,1 \mathrm{ab}$ & $0,17 \mathrm{~cd}$ \\
\hline 2. Vermiculita média & $95 a$ & $98 \mathrm{~ns}$ & $8 a$ & $7,8 \mathrm{ab}$ & $0,44 a$ \\
\hline $\begin{array}{l}\text { 3. Areia } \times \text { vermiculita } \\
(75: 25)\end{array}$ & $78 \mathrm{ab}$ & $85 n s$ & $7 a$ & $6,2 a b$ & $0,28 b$ \\
\hline $\begin{array}{l}\text { 4. Areia } \times \text { vermiculita } \\
(50: 50)\end{array}$ & $85 a$ & $88 \mathrm{~ns}$ & $7 a$ & $7,5 \mathrm{ab}$ & $0,50 \mathrm{a}$ \\
\hline $\begin{array}{l}\text { 5. Areia } \mathrm{x} \text { vermiculita } \\
(25: 75)\end{array}$ & $90 a$ & $90 \mathrm{~ns}$ & $6 a b$ & $8,4 a$ & $0,50 \mathrm{a}$ \\
\hline 6. Esponja fen6lica & $95 a$ & $95 \mathrm{~ns}$ & $6 a b$ & $5,5 \mathrm{ab}$ & $0,24 b c$ \\
\hline 7. Solo & $63 b$ & $85 \mathrm{~ns}$ & $4 b$ & $4,2 b$ & $0,12 d$ \\
\hline C.V. (\%) & 10,5 & 6,7 & 21,8 & 24,8 & 11,3 \\
\hline
\end{tabular}

${ }^{1}$ Médias seguidas da mesma letra nas colunas, não diferem estatisticamente pelo teste de Tukey ao nível de $5 \%$ de probabilidade de erro. 
TAKEYOSHI et al. (1983), verificaram que a vermiculita proporcionou níveis satisfatórios de enraizamento, embora tenha exigido maior tempo para tal, dados concordantes com os obtidos por MULLARD (1954).

A vermiculita é uma mica (silicato hidratado de magnésio, alumínio e ferro) que se expande acentuadamente quando aquecida. Contém suficiente magnésio e potássio para suprir a maioria das necessidades das plantas. Apresenta reação neutra e boa propriedade tampão. É insolúvel e capaz de absorver grandes quantidades de água. Tem uma alta capacidade de troca de cátions, podendo reter nutrientes em reserva e liberá-los mais tarde (HARTMANN \& KESTER, 1975).

Um material que tem apresentado perspectivas de utilização como substrato para enraizamento de estacas é a esponja fenólica. Também chamada de espuma fenólica é um material sintético à base de amidas e resinas poliaminas, apresentando em relação aos substratos estudados o maior espaço poroso total, a maior retenção de água, o maior espaço de ar e a menor densidade (TABELA 1).

Tanto a vermiculita como a esponja fenólica apresentam como vantagem as seguintes propriedades físicas: boa retenção de água $e$ adequado espaço poroso, o que favorece o enraizamento.

\section{CONCLUSÕES}

- O substrato vermiculita média é o mais indicado para o enraizamento de estacas de cróton.

- Os substratos areia $x$ vermiculita, nas proporções de $75 \% \times 25 \%, 50 \% \times 50 \%$ e $25 \% \times 75 \%$ e, esponja fenólica também podem ser utilizados.
- Os substratos solo e areia apresentaram o pior desempenho, não sendo indicados para o enraizamento de estacas apicais de cróton em câmara de nebulização.

\section{REFERÊNCIAS BIBLIOGRÁFICAS}

FIGUEIREDO, E.R. Floricultura brasileira. São Paulo: Chácara e Quintais, 1936. 534p.

GONÇALVES, A.L.; CATHARINO, E.L.M.; TOYOFUKU, R.A. Efeitos de diferentes substratos no enraizamento de estacas apicais e não apicais de Rhipsalis elliptica G.A. Lindberg, Cactaceae. In: CONGRESSO BRASILEIRO DE FLORICULTURA E PLANTAS ORNAMENTAIS, 8., 1991, Joinvile. p.68.

HARTMANN, H.T.; KESTER, D.E. Plant propagation: principles and practices. 3.ed., Englewood Cliffs: Prentice-Hall, 1975.662p.

MULLARD, S.R. Rooting cutting in vermiculite. Journal of the Royal Horticultural Society, London, v.79, p.367-368, 1954.

TAKEYOSHI, N.I.; ANRAKU, R.N.; MINAMI, K.; LIMA, A.M.L.P. Efeitos de diversos substratos no enraizamento de estacas de Chrysanthemum morifolium cv. Polaris. In: CONGRESSO BRASILEIRO DE FLORICULTURA E PLANTAS ORNAMENTAIS, 4., 1983, Rio de Janeiro, Anais... Brasília: EMBRAPA, Departamento de Difusāo de Tecnologia, 1984. p.137142.

PLANTAS de interior. In: ABRIL CULTURAL. Enciclopédia de Plantas e Flores, São Paulo, 1977. p.6-7.

Enviado para publicação em 07.04 .94

Aceito para publicação em 15.07 .93 